\title{
Local Transmission of SARS-CoV-2 Virus in Rome, Italy: A Single Center Experience
}

\author{
Katia Margiotti ${ }^{*}{ }^{(0)}$, Marco Fabiani ${ }^{1}$, Francesca Giorlandino ${ }^{2}$, Marina Cupellaro ${ }^{2}$, \\ Sabrina Emili², Alvaro Mesoraca1, Claudio Giorlandino ${ }^{1,2,3}$ \\ ${ }^{1}$ ALTAMEDICA, Human Genetics Lab, Rome, Italy \\ ${ }^{2}$ ALTAMEDICA, Department of Biochemistry, Rome, Italy \\ ${ }^{3}$ ALTAMEDICA, Department of Prenatal Diagnosis, Fetal-Maternal Medical Centre, Rome, Italy \\ Email: *katia.margiotti@artemisia.it
}

How to cite this paper: Margiotti, K., Fabiani, M., Giorlandino, F., Cupellaro, M., Emili, S., Mesoraca, A. and Giorlandino, C. (2021) Local Transmission of SARS-CoV-2 Virus in Rome, Italy: A Single Center Experience. Advances in Infectious Diseases, 11, 42-48.

https://doi.org/10.4236/aid.2021.111006

Received: January 22, 2021

Accepted: March 7, 2021

Published: March 10, 2021

Copyright $\odot 2021$ by author(s) and Scientific Research Publishing Inc. This work is licensed under the Creative Commons Attribution International License (CC BY 4.0).

http://creativecommons.org/licenses/by/4.0/

\section{(c) (i) Open Access}

\begin{abstract}
In the present study, we analysed the results from the use of serological tests for the evaluation of the antibody response to SARS-CoV-2 virus, with the aim of verifying the seroprevalence for SARS-CoV-2 virus infection in Rome. Evaluations related to the seroprevalence are important for defining the epidemiological parameters of this disease. We therefore analysed the data deriving from 1586 subjects, residing in the geographical area of Rome, subjected to a rapid test, capable of detecting the presence of specific IgM and IgG class antibodies directed against the SARS-CoV-2 virus. Among the 1586 cases, 83 had positive conversion of IgM antibody and/or IgG antibody and 1503 tested negative. Out of 83 positive cases, $48 \%$ (40/83) samples resulted positively for both IgM and IgG, while $45 \%$ (37/83) were positive for IgG only, and 7\% (6/83) for IgM only. The prevalence of anti-SARS-CoV-2 antibodies in the considered geographical area was 5\% (83/1586), and 54\% (45/83) of our population was an asymptomatic carrier. The study was performed to better evaluate the population prevalence in the studied geographic area. To our knowledge, this is the first study carried out in the Lazio region reporting data related to the asymptomatic carriers.
\end{abstract}

\section{Keywords}

COVID-19, SARS-CoV-2 Virus, Antibodies IgM, IgG

\section{Introduction}

The first diagnosis of COVID-19 in Europe has been confirmed in a 38-year-old Italian healthy man. The time between the onset of upper airway symptoms and 
pneumonia was 2 days only. Only 4 days after the onset of COVID-19, the patient was admitted to the intensive unit care of the Policlinico San Matteo in Pavia because of respiratory failure. After weeks of intubation and supportive treatment, the patient luckily recovered and could be discharged in good conditions. Worldwide in less than 4 months spread of COVID-19 which was inevitable, has moved from affecting a few persons in Wuhan (Hubei province, China) to more than 20 million people in almost every country (Coronavirus Research Center, https://coronavirus.jhu.edu/map.html visited on August 21 ${ }^{\text {th }}, 2020$ ) [1] [2]. Economic, social and political distresses caused by this epidemic will certainly impact our country and the entire world in the coming months, probably years. We feel the need to share with the scientific community and others our epidemiological data available as today in the area of Rome, Italy. Hoping that information level keeps high will help to fight and finally stop this pandemic infection. Serologic assays for SARS-CoV-2, now broadly available, can play an important role in understanding the transmission dynamic of the virus in the general population and identifying groups at higher risk for infection. Unlike viral direct detection methods, such as nucleic acid amplification or antigen detection tests that can detect acutely infected persons, antibody tests help determine whether the individual being tested was previously infected even if that person never showed symptoms. These tests can help determine the proportion of a population previously infected with SARS-CoV-2. Thus, demographic and geographic patterns of serologic test results can help determine which communities may have experienced a higher infection rate [3].

As today it is not clear whether a positive serologic test indicates immunity against SARS-CoV-2; at this regard serologic tests should not be used at this time to determine if an individual is immune.

As additional data are collected to understand the significance of the presence or level of antibodies and their correlation with immunity, serologic tests may have utility in infection control decisions, but for now this evidence is not available. In the present work, we analysed the results deriving from the use of a rapid test to evaluate the antibody response in the studied population of 1586 subjects, collected from mid-March to the end of July 2020 in the laboratories of Altamedica in Rome, all subjects were resident in the Roman city.

The aim was to evaluate the percentage of subjects who came into contact with the virus SARS-CoV-2 in this area. Reporting these data, it is very important, as well as evaluating the number of asymptomatic people among the positives population, such information in fact is not often clearly reported in the daily bulletins of the regional health that consider mostly symptomatic cases.

\section{Methods}

\section{Study population}

Between mid-March until the end of July 2020 we enrolled 1586 subjects who voluntarily contacted the Altamedica diagnostic center of Rome, and requested a 
serological test. The studied population resides in the districts of North, East, South, West and Center of Rome, and is composed of asymptomatic subjects, who therefore did not show any symptoms at the time of collection, and of symptomatic subjects who at the time of collection reported symptoms such as fever, and cough (Table 1). A whole blood sample was taken from the home of the subject requesting the test by the medical staff of the Altamedica laboratory in Rome. The study was conducted with the consent of all the participants, and was approved by the internal Ethics Committee of Altamedica Laboratories, Artemisia S.p.A.

\section{Sample Testing}

The IgM antibody and IgG antibody against SARS-CoV-2 in blood samples were tested using 2019-nCOV/COVID-19 IgG/IgM Rapid Test Device (Hangzhou Realy Tech Co., Ltd.) according to the manufacturer's instructions. These

Table 1. Results of the anti-SARS-CoV-2 IgG-IgM antibody test in 1586 samples.

\begin{tabular}{|c|c|c|}
\hline & $\begin{array}{c}\text { SARS-CoV-2 } \\
\text { IgG-IgM positive }\end{array}$ & $\begin{array}{c}\text { SARS-CoV-2 } \\
\text { IgG-IgM negative }\end{array}$ \\
\hline Samples analyzed & $83(5 \%)$ & $1503(95 \%)$ \\
\hline Median age (IQR*) & $43(32-55)$ & $46(35.5-56)$ \\
\hline \multicolumn{3}{|l|}{ Sex } \\
\hline Male & $36(43 \%)$ & $722(48 \%)$ \\
\hline Female & $47(57 \%)$ & $781(52 \%)$ \\
\hline \multicolumn{3}{|l|}{ Age, years } \\
\hline $4-20$ & $5(6 \%)$ & NA \\
\hline $21-64$ & $72(87 \%)$ & NA \\
\hline$\geq 65$ & $6(7 \%)$ & NA \\
\hline Presenting symptoms & $38(45 \%)$ & $95(6.3 \%)$ \\
\hline Fever & $21(25 \%)$ & $38(2.5 \%)$ \\
\hline Cough & $4(4.8 \%)$ & $16(1 \%)$ \\
\hline Bronchitis & $1(1.2 \%)$ & ND \\
\hline Fever, diarrhea & $1(1.2 \%)$ & $23(1.5 \%)$ \\
\hline Fever, Cough, Olfactory and Gustatory dysfunctions & $2(2.4 \%)$ & ND \\
\hline Olfactory and Gustatory dysfunctions & $3(3.6 \%)$ & $7(0.4 \%)$ \\
\hline Olfactory and Gustatory dysfunctions, Fever & $2(2.4 \%)$ & $5(0.5 \%)$ \\
\hline Olfactory dysfunction & $4(4.8 \%)$ & $2(0.1 \%)$ \\
\hline Gastrointestinal dysfunction & ND & $4(3 \%)$ \\
\hline \multicolumn{3}{|l|}{ Laboratory results } \\
\hline IgG-positive & $37(45 \%)$ & ND \\
\hline IgM-positive & $6(7 \%)$ & ND \\
\hline IgG \& IgM-positive & $40(48 \%)$ & ND \\
\hline
\end{tabular}

${ }^{*} \mathrm{IQR}=$ Interquartile range; $\mathrm{ND}=$ Not Detected; NA = Not Analyzed. 
reagents are supplied by Hangzhou Realy Tech Co., Ltd. and resulted CE marked and regularly registered with the Ministry of Italian Health as an IVD Medical Device at N. 1923329. Briefly, the device was opened immediately before use. Refrigerated blood samples used for the test, are warmed to room temperature. During testing, $20 \mathrm{uL}$ whole blood samples are pipetted into the sample port followed by adding 2 drops (about $20 \mathrm{uL}$ ) of dilution buffer to drive capillary action along the strip. The entire test took about $15 \mathrm{~min}$ to finish.

\section{Results and Discussion}

1586 subjects were tested for COVID-19 infection, evenly distributed between men and women ( $48 \%$ vs. $52 \%)$. Age and gender are detailed in Table 1. All samples were tested for viral antibody with a 2019-nCOV/COVID-19 IgG/IgM Rapid Test Device (Hangzhou Realy Tech Co., Ltd.) [4]. The sample studied is shown in Figure 1, 5\% (83/1586) of the analysed subjects resulted in SARS-CoV-2 virus infected, while $95 \%(1503 / 1586)$ had no positive results for the serological test (Table 1). Among the SARS-CoV-2 positive subjects, $48 \%$ (40/83) were positive

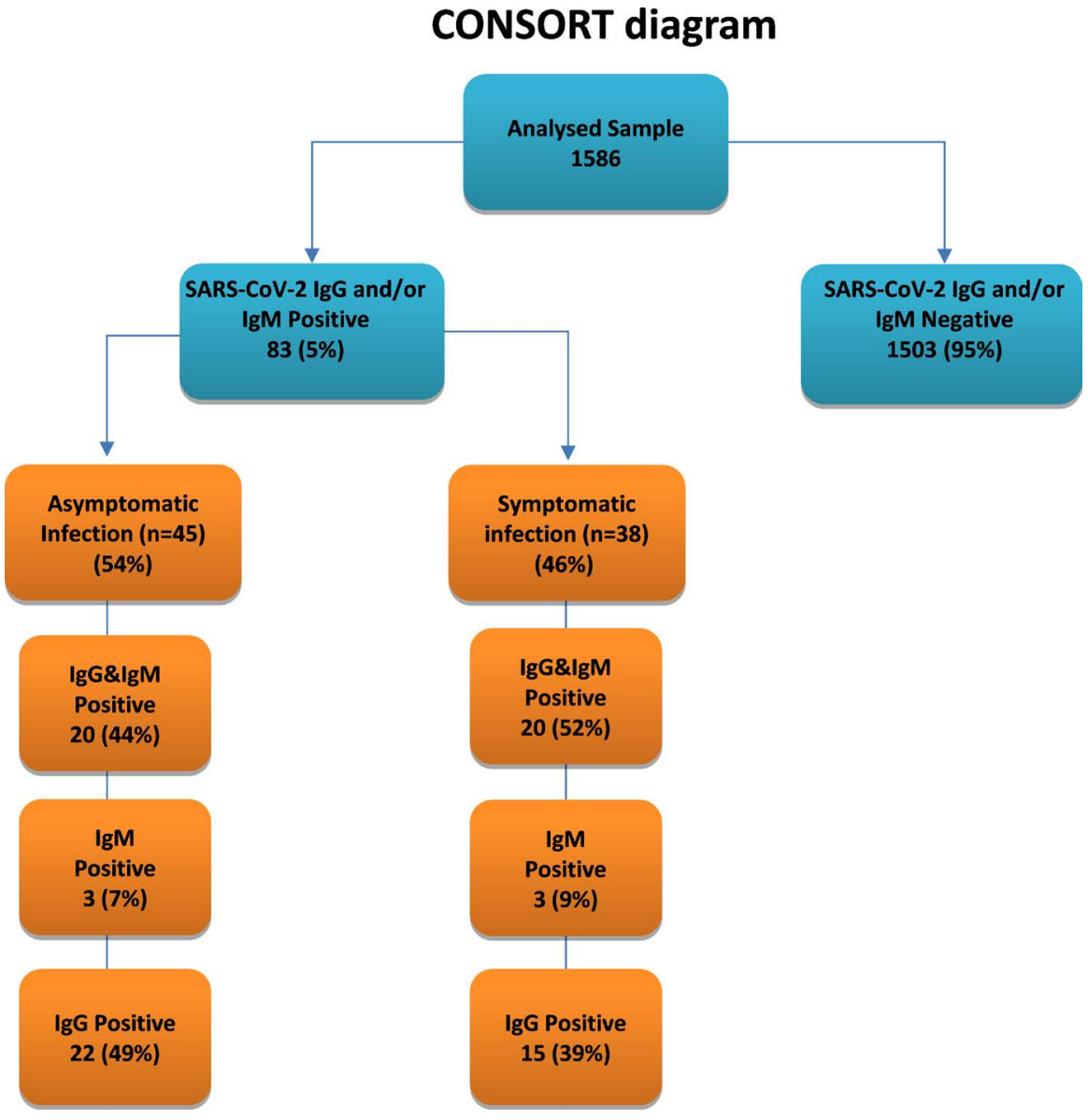

Figure 1. From mid-March 2020, 1586 subjects were analyzed in the Altamedica laboratories, of which 1503 were negative, and 83 were positive for antibodies response directed towards the SAR-CoV-2 virus. Among positive 54\% were asymptomatic and $46 \%$ were symptomatic carriers. 
for both $\operatorname{IgM}$ and $\operatorname{IgG}$, while $45 \%$ (37/83) were positive for IgG only, and $7 \%$ $(6 / 83)$ only for IgM (Table 1). Our data has shown that the infection is contracted often by female than male individuals with a ratio of $43 \%$ against $57 \%$ (36/83 males and $47 / 83$ females) (Table 1). Furthermore, in 54\% (45/83) of the subjects who contracted the virus, the clinical future that accompanied the infection was negative, while $46 \%(38 / 83)$ of the subjects who contracted the virus were symptomatic or paucisymptomatic (Table 2).

Males showed no symptoms of disease in approximately $44 \%$ (20/45) of cases, similar females reported no significant symptoms in 56\% (25/45) of cases (Table 2). Among the symptoms, the most frequent was fever, followed by olfactory, and gustatory dysfunction (Table 1).

According to what is currently known about the natural history of specific immunity to SARS-CoV-2, IgM should become negative about 7 weeks after the first antibody response that occurs about $8-12$ days after the infection onset, while the IgG appears about 14 days and persists for a longer time [5] [6] [7] [8] [9].

From what emerged, it can therefore be assumed that in $48 \%(40 / 83)$ of the subjects having both IgG and IgM the infection occurred in the last 2 months. While in the $45 \%$ (37/83) of the subjects having only class G immunoglobulins, denoting an infection dating back more than 7 weeks [9] (Table 1). In 6 cases $7 \%(6 / 83)$ of the subjects presented only the immunoglobulin class $M$, without IgG, a fact that was given the current knowledge on antibody dynamics, would depose for an infection that occurred no more than 3 weeks before the serological test date, since after three weeks, positive conversion of both IgG and IgM was expected in almost $100 \%$ of the affected subjects [10]. From the literature the longevity of the antibody response is still unknown, but it is known that antibodies to

Table 2. Epidemiological and laboratory results of 83 patients positive to SARS-CoV-2 IgG-IgM in Altamedica S.p.A. laboratories.

\begin{tabular}{ccc}
\hline & $\begin{array}{c}\text { Asymptomatic Infection } \\
(\mathbf{n}=45)\end{array}$ & $\begin{array}{c}\text { Symptomatic Infection } \\
(\mathbf{n}=38)\end{array}$ \\
\hline Age & $3(6.7 \%)$ & $2(5 \%)$ \\
Age $4-20$ & $39(86.7 \%)$ & $33(87 \%)$ \\
Age $21-64$ & $3(6.7 \%)$ & $3(8 \%)$ \\
Age $\geq 65$ & & $16(42 \%)$ \\
Sex & $20(44 \%)$ & $22(58 \%)$ \\
Male & $25(56 \%)$ & \\
Female & & $15(39 \%)$ \\
Laboratory results & $22(49 \%)$ & $3(9 \%)$ \\
IgG-positive & $3(7 \%)$ & $20(52 \%)$ \\
IgM-positive & $20(44 \%)$ & \\
IgG \& IgM-positive & & \\
\hline
\end{tabular}


other coronaviruses wane over time (range: 12 - 52 weeks from the onset of symptoms) and homologous re-infections have been shown [11]. Has been shown that SARS-CoV-2 IgM and IgG antibody levels may remain over the course of 7 weeks [9]. In comparison, $90 \%$ and $50 \%$ of SARS-CoV-1 infected patients have been shown to maintain IgG antibodies for two and three years respectively [12]. Longitudinal serological studies that follow patients' immunity over an extended period of time would be required to study the duration of immunity. Reinfections with all seasonal coronaviruses occur in nature, usually within three years [13]. Based on the minimum infection intervals and the observed dynamics of antibody waning has been showed that the duration of protective immunity may last 6 to 12 months [13].

Although the present epidemiological study still reports a sample that is too small to be recognized as valid for the whole population, important conclusions can still be discussed: i) first of all it appears evident that in the cohort analysed $5 \%$ of the subjects were infected and that, therefore, $95 \%$ did not contract the infection and is potentially still at risk of contracting it; ii) it is also important to point out that $54 \%$ of the subjects who contracted the infection were defined asymptomatic; iii) from what emerged from the antibody detections it can be assumed that the infection in $48 \%(40 / 83)$ of the subjects occurred in the last 2 months prior to the sample collection, in fact both IgG and IgM are still present; vi) finally, at the present time only 37 cases out of 1586 showed a potential immunity with the presence of only IgG corresponding to $0.02 \%$ of the population examined, indicating an infection with the virus that took place more than 7 weeks before the serological test date [5] [9].

We can conclude based on the seroprevalence of our sample residing in the city of Rome, that in the recruitment period and in the geographic area considered, the prevalence of anti-SARS-CoV-2 antibodies was 5\%. Moreover, highly attention must be paid to asymptomatic carriers since they are one of the most important infection origins and can markedly transmit the virus to other individuals [14]. Herein we reported 54\% of asymptomatic carriers evenly distributed between male and female. Overall, with the current transmission patterns it is unlikely that population immunity levels reached soon and will be sufficient for indirect protection at least in the studied geographical region. Although our study is limited to the Roman capital alone, it demonstrates the possibility of estimating and better understanding the progression of this pandemic. This tool is also very important to reduce uncertainty about the state of the epidemic, which can have important socio-economic benefits. To our knowledge, this is the first study on a population subjected to antibody screening carried out in the Lazio region reporting data related to the asymptomatic carriers.

\section{Conflicts of Interest}

The authors declare no conflicts of interest regarding the publication of this paper. 


\section{References}

[1] Zhu, N., Zhang, D., Wang, W., Li, X., Yang, B., Song, J., et al. (2020) A Novel Coronavirus from Patients with Pneumonia in China, 2019. The New England Journal of Medicine, 382, 727-733. https://doi.org/10.1056/NEJMoa2001017

[2] Lu, H., Stratton, C.W. and Tang, Y.W. (2020) Outbreak of Pneumonia of Unknown Etiology in Wuhan, China: The Mystery and the Miracle. Journal of Medical Virology, 92, 401-402. https://doi.org/10.1002/jmv.25678

[3] Winter, A.K. and Hegde, S.T. (2020) The Important Role of Serology for COVID-19 Control. The Lancet Infectious Diseases, 20, 758-759. https://doi.org/10.1016/S1473-3099(20)30322-4

[4] Margiotti, K., Cupellaro, M., Emili, S., Mesoraca, A. and Giorlandino, C. (2020) Evaluation of a Rapid Igm-Igg Combined Antibody Test for Sars-Cov-2 Infection: Single Italian Center Study. American Journal of Infectious Diseases, 16, 85-88. https://doi.org/10.3844/ajidsp.2020.85.88

[5] Matricardi, P.M., Dal Negro, R.W. and Nisini, R. (2020) The First, Holistic Immunological Model of COVID-19: Implications for Prevention, Diagnosis, and Public Health Measures. Pediatric Allergy and Immunology, 31, 454-470. https://doi.org/10.1111/pai.13271

[6] Henrickson, S.E. (2020) Learning from Our Immunological History: What Can SARS-CoV Teach Us about SARS-CoV-2? Science Immunology, 5, eabb8618. https://doi.org/10.1126/sciimmunol.abb8618

[7] Mair-Jenkins, J., Saavedra-Campos, M., Baillie, J.K., Cleary, P., Khaw, F.M., Lim, W.S., et al. (2015) The Effectiveness of Convalescent Plasma and Hyperimmune Immunoglobulin for the Treatment of Severe Acute Respiratory Infections of Viral Etiology: A Systematic Review and Exploratory Meta-Analysis. The Journal of Infectious Diseases, 211, 80-90. https://doi.org/10.1093/infdis/jiu396

[8] Pan, Y., Li, X., Yang, G., Fan, J., Tang, Y., Zhao, J., et al. (2020) Serological Immunochromatographic Approach in Diagnosis with SARS-CoV-2 Infected COVID-19 Patients. Journal of Infection, 81, E28-E32. https://doi.org/10.1016/j.jinf.2020.03.051

[9] Xiao, D.A.T., Gao, D.C. and Zhang, D.S. (2020) Profile of Specific Antibodies to SARS-CoV-2: The First Report. Journal of Infection, 81, 147-178. https://doi.org/10.1016/j.jinf.2020.03.012

[10] He, J., Hu, P., Gao, Y., Zheng, S., Xu, C., Liu, R., et al. (2020) Comparison and Application of Different Immunoassay Methods for the Detection of SARS-CoV-2. Journal of Medical Virology, 92, 2777-2784. https://doi.org/10.1002/jmv.26187

[11] Kellam, P. and Barclay, W. (2020) The Dynamics of Humoral Immune Responses Following SARS-CoV-2 Infection and the Potential for Reinfection. Journal of General Virology. https://doi.org/10.20944/preprints202004.0377.v1

[12] Wu, L.P., Wang, N.C., Chang, Y.H., Tian, X.Y., Na, D.Y., Zhang, L.Y., et al. (2007) Duration of Antibody Responses after Severe Acute Respiratory Syndrome. Emerging Infectious Diseases, 13, 1562-1564. https://doi.org/10.3201/eid1310.070576

[13] Edridge, A.W.D., Kaczorowska, J., Hoste, A.C.R., et al. (2020) Seasonal Coronavirus Protective Immunity Is Short-Lasting. Nature Medicine, 26, 1691-1693. https://doi.org/10.1038/s41591-020-1083-1

[14] Pan, X., Chen, D., Xia, Y., Wu, X., Li, T., Ou, X., et al. (2020) Asymptomatic Cases in a Family Cluster with SARS-CoV-2 Infection. The Lancet Infectious Diseases, 20, 410-411. https://doi.org/10.1016/S1473-3099(20)30114-6 